\title{
Saturação do complexo de troca de solos oxídicos com sódio
}

\author{
Antonio T. de Matos ${ }^{1}$, Onofre B. Almeida Neto ${ }^{2} \&$ Mateus P. de Matos ${ }^{3}$ \\ ${ }^{1}$ UFV. Viçosa, MG. E-mail: atmatos@ufv.br (Autor correspondente) \\ ${ }^{2}$ Instituto Federal de Educação, Ciência e Tecnologia do Sudeste de Minas Gerais. Rio Pomba, MG. E-mail: onofre.neto@ifsudestemg.edu.br \\ ${ }^{3}$ UFMG. Belo Horizonte, MG. E-mail: matmatos_eaa@yahoo.com.br
}

\section{Palavras-chave:}

dispersão

porcentagem de sódio trocável relação de sódio trocável sodificação

\begin{abstract}
R E S U M O
Propôs-se, neste trabalho, avaliar a influência de características físicas, químicas e mineralógicas de três solos oxídicos no potencial de sua sodificação. Nesta avaliação foram utilizadas amostras coletadas no horizonte B, de um Latossolo Vermelho-Amarelo, Latossolo Vermelho e um Argissolo Vermelho, que apresentavam, respectivamente, presença marcante dos minerais caulinita, hematita e gibbsita. As amostras foram caracterizadas em termos físicos, químicos e mineralógicos e, após seu acondicionamento em colunas de solo, submetidas à percolação de soluções com condutividade elétrica (CE) de $8,0 \mathrm{dS} \mathrm{m}^{-1}$ e relação de adsorção do sódio (RAS) de 0, 10, 20, 30, 40 e $50\left(\mathrm{mmol}_{\mathrm{c}} \mathrm{L}^{-1}\right)^{0,5}$, em três repetições. A porcentagem de sódio trocável (PST) e a relação de sódio trocável (RST) foram obtidas por cálculo a partir dos valores de concentração trocável de sódio nos solos. O aumento na RAS da solução de percolação proporcionou aumento nas RST e PST em todos os solos e foi influenciado pela mineralogia, grau de intemperismo e conteúdo de argila. Os solos analisados podem receber águas com RAS e CE altas sem sofrer sodificação expressiva.
\end{abstract}

\section{Key words:}

soil dispersion

exchangeable sodium percentage

exchangeable sodium ratio

sodification

\section{Saturation of the exchange complex of oxidic soils with sodium}

\begin{abstract}
A B S T R A C T
This study investigated the influence of physical, chemical and mineralogical properties of three oxidic soils in their potential sodification. In this evaluation, samples collected in the B horizon of two Oxisol and a Ultisol were used, which presented, respectively, high presence of the mineral kaolinite, hematite and gibbsite. Samples were subjected to physical, chemical and mineralogical analysis and filled soil columns were submitted to leaching with solutions of electrical conductivity (CE) of $8.0 \mathrm{dS} \mathrm{m}^{-1}$ and sodium adsorption ratio (SAR) $0,10,20,30,40$ and $50\left(\mathrm{mmol} \mathrm{L}^{-1}\right)^{0.5}$, in three replications. The exchangeable sodium percentage (ESP) and exchangeable sodium adsorption ratio (ESR) were obtained by calculation from the values of exchangeable sodium in the soil. The increase in the SAR of percolation solution provided an increase in the ESR and ESP of all soils and was influenced by the mineralogy, weathering degree and clay content of soil. The analysed soils can receive waters with high SAR and EC without suffering significant sodification.
\end{abstract}

\section{INTRODUÇÃO}

A dispersão de agentes cimentantes dos agregados do solo é um fenômeno que pode ocorrer naturalmente ou por ação antrópica estando, em geral, associada a desequilíbrios químicos no solo. A resistência do solo à ação dos agentes desagregantes depende de suas características químicas, físicas e mineralógicas. Como consequência de sua dispersão a argila se torna passível de transporte sob condições de chuva, irrigação e fertirrigação para horizontes subsuperficiais do solo, proporcionando diminuição da macroporosidade do meio e com isto, sua permeabilidade (Matos, 2010). Com a perda na permeabilidade ocorre diminuição na capacidade de drenagem e no aumento na deficiência de aeração, no encrostamento superficial e dos processos de contração e expansão em ciclos de umedecimento e secagem do solo. Assis Júnior \& Silva (2012) verificaram que água de poço contendo alta concentração de sais alterou os atributos físicos densidade do solo, argila dispersa em água e grau de floculação de um Neossolo Flúvico Ta eutrófico.

Rengasamy (1983) verificou menor dispersão da argila em solos contendo maiores teores de cálcio e magnésio enfatizando que cátions polivalentes formam pontes de cátions com partículas carregadas negativamente aumentando sua agregação. Paliwal \& Gandhi (1976) observaram maior potencial de sodificação em solos mais arenosos que argilosos ao que atribuíram ao maior poder-tampão desses últimos. Solos altamente intemperizados, como Latossolos e Argissolos, embora apresentem mineralogia semelhante já que há dominância de caulinita, goethita, hematita e gibbsita na fração argila, podem apresentar reações e comportamentos bem diferenciados, o que se atribui principalmente aos diferentes ambientes de sua formação (Schaefer et al., 2008).

Além de características mineralógicas, físicas e químicas do solo, a qualidade da água em equilíbrio com a fase sólida do 
solo também está diretamente associada à dispersão da argila do solo sendo as principais a relação de adsorção de sódio (RAS) e a condutividade elétrica (CE) (Matos, 2010).

A RAS expressa o equilíbrio de cátions monovalentes $(\mathrm{Na})$ com divalentes (Ca e Mg) obtida com base na equação de Gapon (Dikinya et al., 2007). Outras variáveis que têm sido utilizadas na estimativa da tendência à dispersão e instabilidade dos agregados são a porcentagem de sódio trocável (PST) e a relação de sódio trocável (RST) (Paliwal \& Gandhi, 1976).

Solos com dominância de argilas do grupo das esmectitas dispersam espontaneamente, quando há redução na $\mathrm{CE}$ ou aumento na RAS da solução do solo, condições que proporcionam mudanças na distribuição de poros por tamanho e decréscimo na condutividade hidráulica do solo, em meio saturado (Dikinya et al., 2006). Arienzo et al. (2012) afirmaram que RAS menor que $5\left(\mathrm{mmol} \mathrm{L}^{-1}\right)^{0,5}$ causou pequenos efeitos adversos em solo esmectítico e que apenas altos valores de RAS, quando há redução na concentração de eletrólitos na água do solo, podem ocasionar decréscimo na sua condutividade hidráulica. Dikinya et al. (2007) observaram efeitos evidentes da mineralogia do solo tendo havido também maior redução na condutividade hidráulica de material esmectítico-caulinítico que em caulinítico com aumento da RAS.

A fertirrigação com águas residuárias urbanas, agroindustriais e do criatório de animais, pode resultar na adição de grandes quantidades de sais proporcionando alteração nas proporções dos diversos cátions no solo, incluindo sódio e potássio e com isso comprometer suas propriedades físico-hídricas, além do crescimento das plantas (Matos, 2010). Estudos a respeito das relações de sódio e potássio com o complexo de troca do solo de diferentes mineralogias são importantes para o gerenciamento adequado de áreas nas quais sejam aplicadas águas residuárias (Arienzo et al., 2012).

A diluição e a retirada de sais solúveis do solo podem ser efetuadas mediante a aplicação de lâminas de lixiviação as quais podem, muitas vezes, diluir, juntamente com sais dispersantes, sais agregantes, comprometendo a estrutura do solo com efeitos notórios na estabilidade de agregados, porosidade e densidade, entre outros atributos físicos do solo (Miranda et al., 2011). Assim, o fornecimento de íons com força de agregação no solo assume papel relevante e, na recuperação de solos sodificados, recomenda-se que a definição da dose de gesso a ser aplicada seja baseada no PST considerado aceitável para o solo (Harron et al., 1983).

Os valores de PST e RST na camada superficial do solo podem ser estimados com razoável acuracidade, a partir do valor da RAS na água aplicada de vez que ocorre relativamente rápido equilíbrio químico entre eles sendo, por isso, bons indicadores do acúmulo potencial de sódio trocável (Bresler, 1982).

Freire et al. (2003) observaram forte influência da mineralogia da argila do solo na saturação do complexo de troca com sódio sendo que solos contendo esmectita apresentaram maior saturação por sódio que os predominantemente cauliníticos. Por outro lado e no que se refere à solução do solo, Paliwal \& Gandhi (1976) observaram que RST e PST aumentaram com o decréscimo na razão Ca: $\mathrm{Mg}$, o que atribuem à maior dificuldade para o sódio deslocar o cálcio que o magnésio do complexo de troca do solo.

Muitas equações, baseadas na equação de Gapon, têm sido apresentadas na literatura para relacionar RST com a RAS. Em razão de diversos fatores interferirem na relação de RST e PST com a RAS, é inadequada a utilização de equações desenvolvidas para solos de outras partes do mundo e por isso foram sugeridos estudos de equilíbrio entre o sódio em solução e o sódio trocável, em solos brasileiros (Freire, 2001).

Considerando-se a real possibilidade de sodificação de solos mais intemperizados, decorrente da aplicação de águas residuárias ricas em sódio, estudos e a obtenção de equações para estimativa de PST e RST, como função da RAS se tornam importantes razão por que se objetivou, no presente trabalho, avaliar a influência de características físicas, químicas e mineralógicas de três solos oxídicos no potencial de sua sodificação, além de se obter equações que relacionem as concentrações de sódio trocável com as da solução.

\section{Material e Métodos}

Para avaliação da influência de algumas características físicas, químicas e mineralógicas na magnitude dos efeitos de soluções com diferentes valores de RAS sobre o solo, foram utilizadas amostras de solos coletadas no horizonte B de um Latossolo Vermelho-Amarelo (LVA) do município de Viçosa; Latossolo Vermelho (LV), do município de Belo Horizonte e um Argissolo Vermelho (PV), do município de Barroso, todos do estado de Minas Gerais, Brasil, sendo essas classes de solo escolhidas por apresentarem, respectivamente, presença marcante dos minerais caulinita, hematita e gibbsita.

Depois de efetuada a coleta as amostras de solos foram secadas ao ar, destorroadas e passadas em peneira de $2 \mathrm{~mm}$, para sua caracterização física, química e mineralógica. As análises físicas compreenderam a determinação da textura, conforme EMBRAPA (1997) cujos resultados estão apresentados na Tabela 1.

As análises químicas incluíram a quantificação das concentrações de cátions trocáveis $\left(\mathrm{Ca}^{2+}, \mathrm{Mg}^{2+}, \mathrm{K}^{+}\right.$e $\left.\mathrm{Na}^{+}\right)$, acidez trocável $\left(\mathrm{Al}^{3+}\right)$, acidez total $(\mathrm{H}+\mathrm{Al})$, matéria orgânica e fósforo disponível (EMBRAPA, 1997). Os teores de potássio e sódio trocáveis foram obtidos por fotometria de chama, os de cálcio e magnésio por absorção atômica, os de fósforo e ferro por colorimetria e a acidez trocável e acidez potencial por titulometria (EMBRAPA, 1997). Os valores da soma de bases (S),

Tabela 1. Análise granulométrica obtida em amostra de um Latossolo Vermelho-Amarelo (LVA), Latossolo Vermelho (LV) e Argissolo Vermelho (PV)

\begin{tabular}{lccrc}
\hline \multirow{3}{*}{ Solo } & \multicolumn{5}{c}{ Fração } \\
\cline { 2 - 5 } & Areia grossa & Areia fina & Silte & Argila \\
\cline { 2 - 5 } LVA & 12 & 8 & 5 & 75 \\
LV & 32 & 5 & 17 & 46 \\
PV & 19 & 8 & 29 & 44 \\
\hline
\end{tabular}


Tabela 2. Caracterização química obtida em amostra de um Latossolo Vermelho-Amarelo (LVA), Latossolo Vermelho (LV) e Argissolo Vermelho (PV)

\begin{tabular}{|c|c|c|c|c|c|c|c|c|c|c|c|c|c|}
\hline \multirow{2}{*}{ Solo } & $\mathbf{P}$ & K & $\mathrm{Na}$ & $\mathrm{Ca}^{2+}$ & $\mathrm{Mg}^{2+}$ & $\mathrm{Al}^{3+}$ & $\mathrm{H}+\mathrm{Al}$ & SB & (t) & (T) & ISNa & PST & \multirow{2}{*}{$\begin{array}{c}\text { MO } \\
\text { dag } \mathrm{kg}^{-1}\end{array}$} \\
\hline & \multicolumn{3}{|c|}{$\mathrm{mg} \mathrm{dm}^{-3}$} & \multicolumn{7}{|c|}{$\mathrm{cmol}_{\mathrm{c}} \mathrm{dm}^{-3}$} & \multicolumn{2}{|c|}{$\%$} & \\
\hline LVA & 2,0 & 50 & 12,4 & 0,16 & 0,16 & 0,65 & 12,6 & 0,50 & 1,15 & 13,10 & 4,69 & 0,41 & 0,50 \\
\hline LV & 2,3 & 58 & 13,4 & 0,25 & 0,17 & 0,55 & 12,0 & 0,63 & 1,18 & 12,63 & 4,94 & 0,46 & 2,38 \\
\hline PV & 1,3 & 34 & 1,4 & 3,71 & 0,56 & 0,25 & 12,9 & 4,37 & 4,62 & 17,27 & 0,13 & 0,04 & 1,44 \\
\hline
\end{tabular}

$\mathrm{P}, \mathrm{Na}, \mathrm{K}$ - Extrator Mehlich 1; Ca, Mg e Al - Extrator: KCl 1 mol L-1; $\mathrm{H}+\mathrm{Al}$ - Extrator acetato de cálcio 0,5 mol L-11 pH 7,0; SB - Soma de bases trocáveis; $\mathrm{t}$ - Capacidade de troca catiônica efetiv;a T - Capacidade de troca catiônica; ISNa - Índice de saturação por sódio $=\left[\mathrm{Na}^{+}\right] / t$; PST - Porcentagem de sódio trocável = $\left[\mathrm{Na}^{+}\right] / 7$; MO - material orgânica $=\mathrm{C} .0 \mathrm{rg}$. $\times 1,724-$ método WalkleyBlack (Matos, 2012)

capacidade de troca catiônica efetiva $(\mathrm{t})$ e potencial $(\mathrm{T})$, índice de saturação por sódio (ISNa) e porcentagem de sódio trocável (PST) foram obtidos por meio de cálculos que envolveram os cátions trocáveis determinados. Na Tabela 2 se apresenta a caracterização química dos solos estudados.

Para a análise mineralógica da fração argila do solo, amostras de terra fina secada ao ar (TFSA), de aproximadamente 10 $\mathrm{g}$, foram dispersas pela adição de $100 \mathrm{~mL}$ de $\mathrm{NaOH} 0,1 \mathrm{~mol}$ $\mathrm{L}^{-1}$, seguindo a agitação em coqueteleira, durante $15 \mathrm{~min}$. A suspensão obtida foi passada em peneira com malha de 0,053 mm separando-se a fração areia (EMBRAPA, 1997). As frações remanescentes (silte e argila) foram suspensas em solução aquosa, de pH 10 ( $\mathrm{pH}$ elevado pela adição de $\mathrm{Na}_{2} \mathrm{CO}_{3}$ ) e, posteriormente, separadas por sifonamento. $\mathrm{O}$ material argiloso recebeu tratamento com $\mathrm{H}_{2} \mathrm{O}_{2}$, a quente, para eliminação da matéria orgânica sendo posteriormente secado ao ar e moído em almofariz.

A argila foi analisada em difratômetro com radiação de cobalto (comprimento de onda de 1,5418 A) e filtro de níquel, com velocidade de exposição de $1^{\circ} \mathrm{min}^{-1}$; na Figura 1 se apresentam os espectros da fração argila dos solos estudados.

Os tratamentos corresponderam à aplicação nos três solos de cada uma das soluções de percolação preparadas com CE de $8,0 \mathrm{dS} \mathrm{m}^{-1}$ e RAS de $0,10,20,30,40$ e $50\left(\mathrm{mmol}_{\mathrm{c}} \mathrm{L}^{-1}\right)^{0.5}$, em três repetições, totalizando 54 unidades experimentais; para obtenção dos valores especificados para CE e RAS foram utilizados os sais $\mathrm{NaCl}$ e $\mathrm{CaCl}_{2}$ no preparo dessas soluções.

As concentrações molares de sódio e cálcio nas soluções foram calculadas a partir dos valores de RAS e da CE definidas $\left(8 \mathrm{dS} \mathrm{m}^{-1}\right)$, segundo o desenvolvimento a seguir:

$$
\operatorname{RAS}=\frac{\left[\mathrm{Na}^{+}\right]}{\sqrt{\frac{\left[\mathrm{Ca}^{2+}\right]+\left[\mathrm{Mg}^{2+}\right]}{2}}}
$$

Utilizando a aproximação a seguir, válida para o experimento em questão, no qual não foram utilizados sais de magnésio: $\left[\mathrm{Ca}^{2+}\right]+\left[\mathrm{Mg}^{2+}\right] \approx\left[\mathrm{Ca}^{2+}\right]$, a expressão para a RAS se resume a:

$$
\mathrm{RAS}=\frac{\left[\mathrm{Na}^{+}\right]}{\sqrt{\frac{\left[\mathrm{Ca}^{2+}\right]}{2}}} \rightarrow\left[\mathrm{Na}^{+}\right]=\mathrm{RAS} \times \sqrt{\frac{\left[\mathrm{Ca}^{2+}\right]}{2}}
$$

Assumindo que $\left[\mathrm{Na}^{+}\right]+\left[\mathrm{Ca}^{2+}\right]=10 \times \mathrm{CE}$ (Bresler, 1982), $\left[\mathrm{Ca}^{2+}\right]=10 \times \mathrm{CE}-\left[\mathrm{Na}^{+}\right]$e substituindo na Eq. 2 , pode-se obter:
A.

Argila: LVA
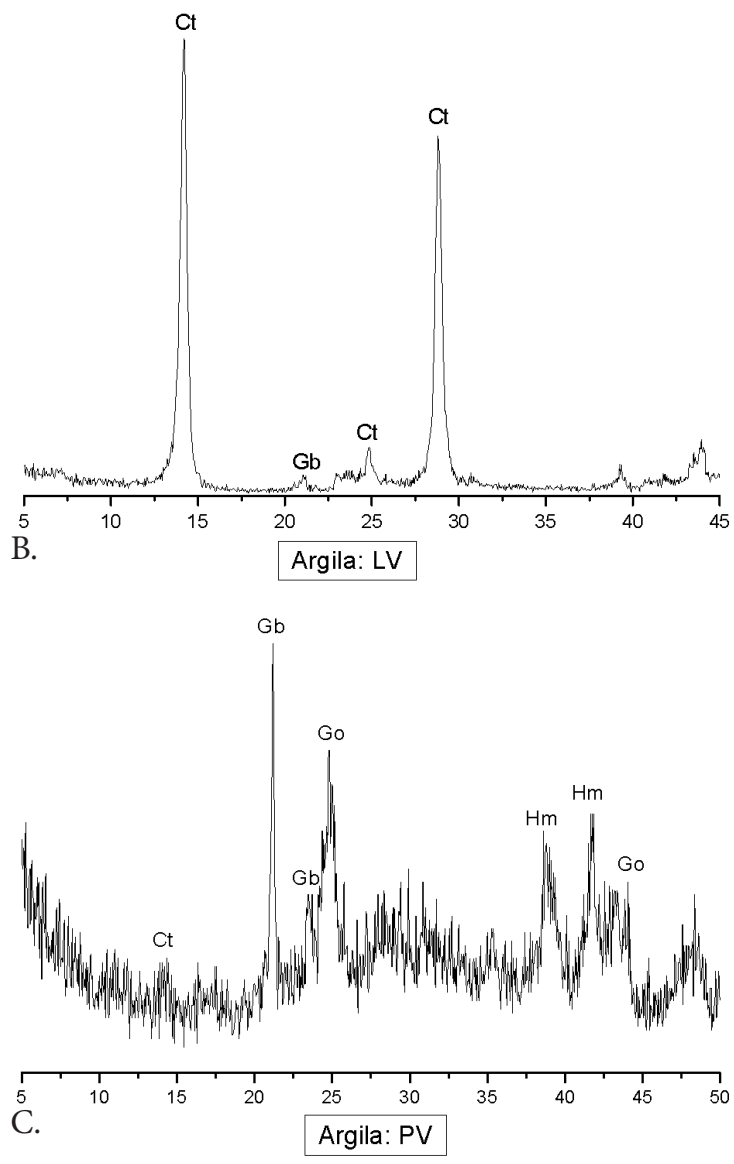

$\mathrm{Gb}$

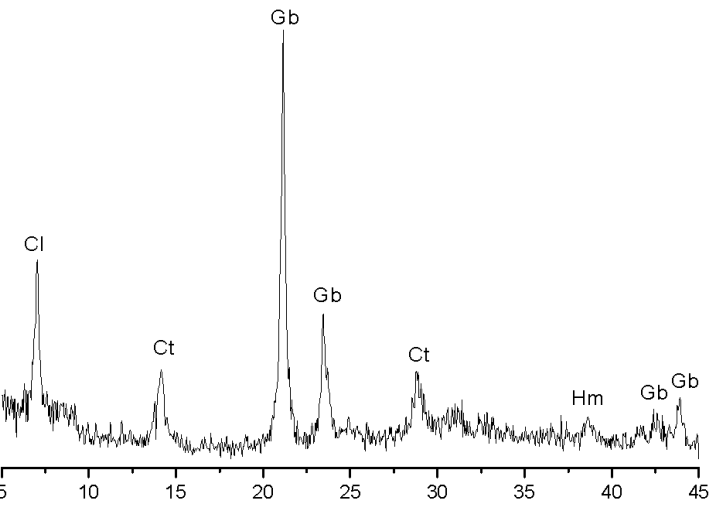

Figura 1. Difratogramas de raio-x da fração argila obtida em amostra de um Latossolo VermelhoAmarelo (LVA), Latossolo Vermelho (LV) e Argissolo Vermelho (PV). Sendo: Gb - Gibbsita, Hm - Hematita, Go - Goethita, Ct - Caulinita e Qz - Quartzo e Cl Clorita 


$$
\left[\mathrm{Na}^{+}\right]=\mathrm{RAS} \times \sqrt{\frac{10 \times \mathrm{CE}-\left[\mathrm{Na}^{+}\right]}{2}}
$$

Desenvolvendo a Eq. 3 e elevando ao quadrado os dois lados e os rearranjando, obtém-se uma equação de $2^{\circ}$ grau em que a $\left[\mathrm{Na}^{+}\right]$é a incógnita em questão; calculando as raízes de forma que a $\left[\mathrm{Na}^{+}\right]$na solução a ser preparada seja função da RAS e da CE desejadas em dado tratamento, obtém-se:

$$
\left[\mathrm{Na}^{+}\right]=\frac{-\mathrm{RAS}^{2}+\sqrt{\mathrm{RAS}^{4}+80 \times \mathrm{CE} \times \mathrm{RAS}^{2}}}{4}
$$

As massas de $\mathrm{NaCl}$ e $\mathrm{CaCl}_{2}$ utilizadas no preparo das soluções salinas estão apresentadas na Tabela 3 .

Para obtenção da condição de equilíbrio iônico entre as diferentes soluções salinas e os materiais dos três solos, foram conduzidos ensaios dinâmicos nos quais essas soluções foram aplicadas e percoladas em colunas de solo acondicionadas em tubos de PVC de $5 \mathrm{~cm}$ de diâmetro e $20 \mathrm{~cm}$ de comprimento. Para minimizar a ocorrência de escoamento preferencial junto às paredes internas dos tubos suas superfícies internas foram impregnadas com areia lavada fixada por cola. A parte inferior dessas colunas foi fechada com tela forrada com um disco de lã de vidro, sendo o solo acondicionado, tomando-se o cuidado de homogeneizar a distribuição das partículas para evitar a formação de camadas de compactação diferenciada, até uma altura de $10 \mathrm{~cm}$, de acordo com a massa específica do solo. $\mathrm{Na}$ parte superior da coluna foi colocado outro disco de lã de vidro para evitar distúrbios na superfície quando da passagem das soluções salinas.

Primeiro, as colunas foram colocadas para saturar dentro de bandejas plásticas, contendo a solução de percolação, conforme o tratamento até uma altura correspondente a aproximadamente dois terços da altura da amostra de solo $(7 \mathrm{~cm})$ e assim permaneceram por, no mínimo, $48 \mathrm{~h}$, conforme adaptado de Freire (2001), quando foram montados os permeâmetros de coluna vertical e carga constante. A seguir realizou-se, em regime permanente e em meio saturado, a aplicação das soluções salinas de percolação utilizando-se, para tal, frascos "Mariotte" como sistema de alimentação. A solução de percolação (Tabela 3) foi aplicada até o momento em que a CE do efluente se aproximou da afluente. Posteriormente, as colunas de solo foram mantidas nos recipientes com as soluções de percolação por no mínimo mais $24 \mathrm{~h}$, conforme adaptado de Freire (2001). Findo este período, amostras de material de solo das colunas foram retiradas para análise da concentração de sódio trocável, conforme metodologia já descrita.

Tabela 3. Valores da relação de adsorção de sódio (RAS), concentrações e massas de cloreto de sódio e cloreto de cálcio, utilizados no preparo de $1 \mathrm{~L}$ das soluções de percolação

\begin{tabular}{lcc}
\hline Solo & \multicolumn{1}{c}{ Equação } & $\mathbf{R}^{\mathbf{2}}$ \\
LVA & PST $=0,4307+0,6509^{* \star} \cdot$ RAS $-0,0068^{\star} \cdot$ RAS $^{2}$ & 0,987 \\
LV & PST $=0,9689+0,7208^{*}$. RAS $-0,0083 \cdot$ RAS $^{2}$ & 0,946 \\
PV & PST $=0,4304+0,7778^{\star * *} \cdot$ RAS $-0,0069^{\star *} \cdot$ RAS $^{2}$ & 0,997 \\
\hline
\end{tabular}

A porcentagem de sódio trocável (PST) e a relação de sódio trocável (RST) foram calculadas utilizando-se, respectivamente, as Eqs. 5 e 6.

$$
\begin{gathered}
\text { PST }=\frac{100 \times\left[\mathrm{Na}^{+}\right]}{\mathrm{T}} \\
\text { RST }=\frac{\left[\mathrm{Na}^{+}\right]}{\mathrm{T}-\left[\mathrm{Na}^{+}\right]}
\end{gathered}
$$

em que:

$\left[\mathrm{Na}^{+}\right]$- concentração de sódio trocável no solo, $\mathrm{mmol}_{\mathrm{c}} \mathrm{dm}^{-3}$

$\mathrm{T}$ - CTC potencial do solo, $\mathrm{mmol}_{\mathrm{c}} \mathrm{dm}^{-3}$

Equações matemáticas foram ajustadas por regressão aos dados de PST e RST em função da RAS, utilizando-se o modelo linear para a equação RST $x$ RAS e para a equação PST x RAS avaliaram-se diversos modelos matemáticos optando-se por aquele que apresentasse maior significância dos coeficientes e do valor do coeficiente de determinação.

\section{Resultados e Discussão}

Na Figura 2 estão apresentadas as curvas e as equações lineares ajustadas aos dados de RST em função dos valores de RAS na solução de percolação.

Conforme se verifica, o uso de soluções de diferentes valores de RAS proporcionou aumento da RST, nos três solos estudados. Verifica-se, no entanto, tendência de estabilização na quantidade de sódio adsorvido aos sítios de troca catiônicos com o aumento da RAS. Este comportamento proporcionaria melhor ajuste de modelos quadráticos; entretanto, como na literatura as equações ajustadas para RST em função da RAS são

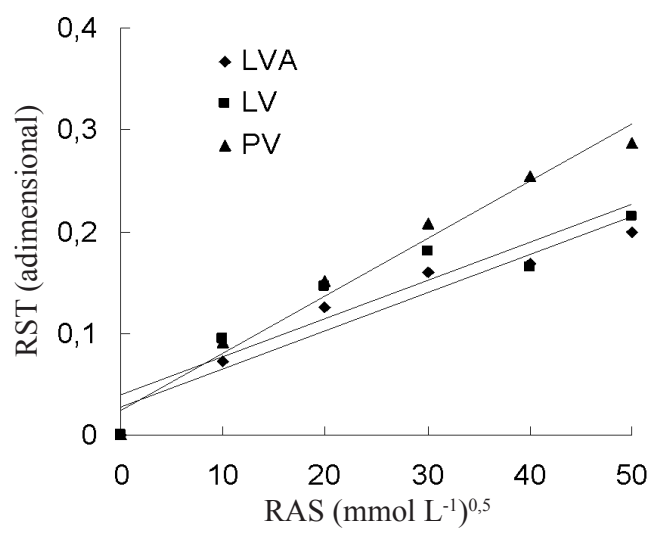

\begin{tabular}{llc}
\hline Solo & \multicolumn{1}{c}{ Equação } & $\mathbf{R}^{\mathbf{2}}$ \\
LVA & RST $=0,0269+0,0038^{* *}$.RAS & 0,921 \\
LV & RST $=0,0391+0,0038^{* *}$.RAS & 0,849 \\
PV & RST $=0,0239+0,0056^{* * *}$. RAS & 0,973 \\
\hline
\end{tabular}

** $e^{* \star *}$ Significância de 0,01 e 0,001, respectivamente

Figura 2. Relação de sódio trocável (RST) em função da relação de adsorção de sódio (RAS) e equações de regressão lineares obtidas em amostra de um Latossolo Vermelho-Amarelo (LVA), Latossolo Vermelho (LV) e Argissolo Vermelho (PV) 
sempre lineares, optou-se por apresentar as equações lineares ajustadas. A razão pela preferência dos pesquisadores pelo ajuste de modelos lineares decorre, segundo Dikinya et al. (2007), do fato de haver a relação teórica RST $=K_{G} \times$ RAS, em que $K_{G}$ é a constante de Gapon.

Comparando os coeficientes angulares das equações ajustadas aos solos estudados, verificam-se menores valores na equação do LVA e LV que na do PV. Embora a gibbsita seja a argila dominante, o PV é um solo mais jovem, o que pode ser comprovado pelo relativamente alto teor de silte que possui (Tabela 1) e pela presença de clorita na fração argila (Figura 1); por isso se apresentou menos resistente à adsorção do sódio. Freire et al. (2003) verificaram que solos mais jovens, que apresentavam esmectita na fração argila, demonstraram maior afinidade no processo de saturação por sódio com pouca interferência da CE da água utilizada, que aqueles que apresentavam maior presença de caulinita. Harron et al. (1983) atribuíram ao maior teor de matéria orgânica no horizonte $\mathrm{A}$, em relação ao B, o menor coeficiente angular obtido na equação ajustada para RST em função da RAS, em um solo solonétzico. Esses autores justificaram que há preferencial adsorção de cátions divalentes que sódio no material orgânico. Avaliando, porém, os conteúdos de matéria orgânica apresentados na Tabela 2, verifica-se que isto não foi fator de influência na adsorção de sódio. Paliwal et al. (1971) observaram tendência do coeficiente angular da regressão aumentar com a diminuição no teor de argila do solo. Nos solos oxídicos estudados essa associação ficou comprovada já que, conforme consta na Tabela 1 , o solo com menor teor de argila (PV) foi o que apresentou o maior coeficiente angular.

Diversos autores estudaram a relação entre RST e RAS estando as equações apresentadas na Tabela 4 . A diferença entre as equações é atribuída à composição mineralógica, aos tipos de sais solúveis de sódio, ao teor de matéria orgânica, ao pH e à presença de carbonato de cálcio.

A equação clássica de Richards (RST $=-0,0126+0,0147 \mathrm{RAS}$ ) tomada por muitos como passível de uso generalizado, diferiu bastante da obtida para solos mais intemperizados, tal como os solos estudados. Comparando o coeficiente angular das equações apresentados na Tabela 4 , verifica-se que as equações obtidas neste trabalho para o LVA e LV se assemelharam muito às obtidas por Paliwal et al. (1971) para solos de textura francoarenosa e arenosa, além da referente à equação geral por eles proposta. A equação ajustada para o PV, por sua vez, aproximouse da obtida por Harron et al. (1983) para o horizonte A de um solo solonétzico do Canadá.
Na Figura 3 se encontram as curvas e as equações quadráticas utilizadas para relacionar PST com a RAS. Diferentemente das curvas RST x RAS têm sido apresentados, na literatura, ajustes de equações diferentes das de primeiro grau para as curvas de PST x RAS, tal como apresentado por Paliwal \& Gandhi (1976) e por esta razão se optou por apresentar equações de melhor ajuste, que foram as de modelo quadrático.

Corroborando com o que foi obtido por outros autores (Dikinya et al., 2007; Freire et al. 2003, Paliwal \& Gandhi, 1976), o aumento na RAS proporciona aumento na PST, tal como já tinha sido verificado em relação à RST devido às trocas iônicas que ocorrem no meio. Verifica-se também que, como não poderia deixar de ser, as curvas PST x RAS apresentam mesmo comportamento das RST x RAS, com igual tendência de haver um limite na substituição de sódio por outros cátions no complexo de troca dos solos. Utilizando as equações ajustadas para estimativa dos valores de PST máximos, obtém-se 16, 16,6 e 22,5\%, respectivamente, para o LVA, LV e PV. Com isto se verifica que a máxima saturação do complexo de troca com $\mathrm{Na}$ é semelhante no LVA e LV sendo, no entanto, maior no PV. Credita-se grande parte desses resultados à sua mineralogia, típica de solo mais jovem, e ao relativamente baixo percentual de argila presente no PV. Freire et al. (2003) apresentaram

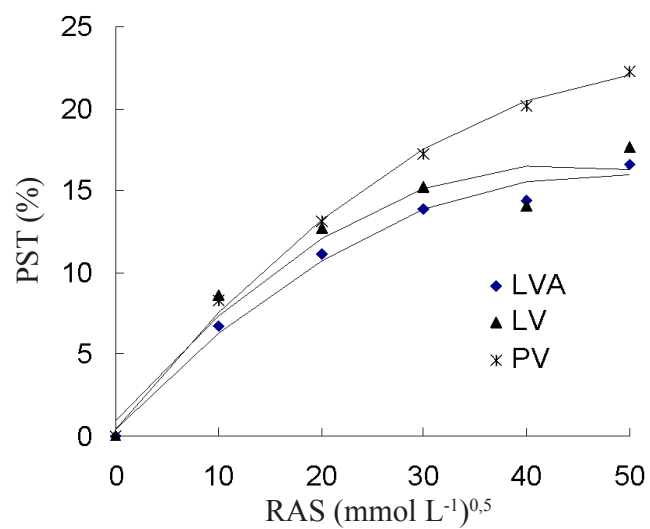

\begin{tabular}{|c|c|c|}
\hline Solo & Equação & $\mathbf{R}^{2}$ \\
\hline LVA & PST $=0,4307+0,6509^{\star *} \cdot$ RAS $-0,0068^{*} \cdot$ RAS $^{2}$ & 0,987 \\
\hline LV & PST $=0,9689+0,7208^{*} \cdot$ RAS $-0,0083 \cdot$ RAS $^{2}$ & 0,946 \\
\hline PV & PST $=0,4304+0,7778^{* \star *}$. RAS $-0,0069 * *$. RAS $^{2}$ & 0,997 \\
\hline
\end{tabular}

** $e^{* * \star}$ Significância de 0,01 e 0,001 , respectivamente

Figura 3. Porcentagem de adsorção de sódio (PST) em função da relação de adsorção de sódio (RAS) e equações de regressão quadráticas obtidas em amostra de um Latossolo Vermelho-Amarelo (LVA), Latossolo Vermelho (LV) e Argissolo Vermelho (PV)

Tabela 4. Equações de regressão determinadas para estimar a relação de sódio trocável (RST) em função da relação de adsorção de sódio (RAS) de solos de diferentes características e regiões do mundo

\begin{tabular}{llll}
\hline \multicolumn{1}{c}{ Equação } & & País (Estado) & Fonte \\
RST $=0,1381+0,00899$. RAS & & Índia & Paliwal \& Gandhi (1976) \\
RST $=0,15+0,0025$. RAS & solo argiloso & Índia & Paliwal et al. (1971) \\
RST $=0,18+0,0029$. RAS & solo franco & Índia & Paliwal et al. (1971) \\
RST $=0,20+0,0036$. RAS & solo franco-arenoso & Índia & Paliwal et al. (1971) \\
RST $=0,32+0,0036$. RAS & solo arenoso & Índia & Paliwal et al. (1971) \\
RST $=0,23+0,0042$. RAS & eq. Geral & Candia & Paliwal et al. (1971) \\
RST $=0,0076+0,0058$. RAS & horiz A solo solonétzico & Harron et al. (1983) \\
RST $=0,0180+0,0173$. RAS & horiz B deum solo solonétzico & Canadá & Harron et al. (1983) \\
\hline
\end{tabular}


curvas indicativas de que a PST máxima no grupo de solos considerados mais intemperizados (Argissolo Vermelho Amarelo, Planossolo Háplico e Argissolo Amarelo) estaria entre 11 e 15\% (valores estimados), com a aplicação de soluções de percolação de CE de $1,5 \mathrm{dS} \mathrm{m}^{-1}$. Os valores obtidos por esses autores podem ser considerados próximos aos obtidos neste trabalho para o LVA e LV, mesmo tendo sido utilizadas soluções de percolação de maior $\mathrm{CE}\left(8,0 \mathrm{dS} \mathrm{m}^{-1}\right)$, indicando que o nível de saturação do complexo de troca desses solos independe da concentração iônica da solução percolante.

Almeida Neto et al. (2009) concluíram, estudando o comportamento dos mesmos solos utilizados neste experimento (LVA, LV e PV), sob condições de percolação de soluções de RAS e CE crescentes, que todas as soluções de percolação, notadamente as de maiores $\mathrm{CE}$, independente do valor da RAS, proporcionaram, ao invés de dispersão, a manutenção ou diminuição na argila dispersa nos solos.

Corroborando com Freire et al. (2003) e com base nos resultados obtidos, pode-se afirmar que solos mais intemperizados suportariam águas de RAS mais elevada, desde que a CE não seja baixa, sem apresentar indicativos de sodificação e dispersão de argila.

\section{Conclusões}

1. A mineralogia, o grau de intemperismo e o conteúdo de argila do solo, influenciam a relação de sódio trocável e a porcentagem de sódio trocável;

2. O aumento na relação de adsorção de sódio nas soluções de percolação eleva a relação de sódio trocável e a porcentagem de sódio trocável nos solos estudados;

3. As equações de estimativa da razão de adsorção de sódio obtidas para o Latossolo Vermelho-Amarelo, Latossolo Vermelho e Argissolo Vermelho, diferiram acentuadamente da equação clássica de Richards, que tem sido utilizada indistintamente para qualquer tipo de solo;

4. Os solos estudados podem receber águas de relação de adsorção de sódio e alta condutividade elétrica, sem sofrer sodificação expressiva.

\section{Literatura Citada}

Almeida Neto, O. B.; Matos, A. T.; Abrahão, W. A. P.; Costa, L. M.; Duarte, A. Influência da qualidade da água de irrigação na dispersão da argila de Latossolos. Revista Brasileira de Ciência do Solo, v.33, p.1571-1581, 2009.

Arienzo, M.; Christen, E. W.; Jayawardane, N. S; Quayle, W. C. The relative effects of sodium and potassium on soil hydraulic conductivity and implications for winery wastewater management. Geoderma, v.173-174, p.303-310, 2012.
Assis Júnior, R. N.; Silva, E. F. Efeito da qualidade da água de irrigação sobre os atributos físicos de um Neossolo Flúvico do município de Quixeré, CE - Brasil Revista Brasileira de Ciência do Solo, v.36, p.1778-1786, 2012.

Bresler, E.; McNeal, B. L.; Carter, D. L.Saline and Sodic Soils. Principles-Dynamics-Modeling. New York: Springer-Verlag, 1982. 236p.

Dikinya, O.; Hinz, C.; Aylmore, G. Dispersion and re-deposition of fine particles and their effects of on saturated hydraulic conductivity. Australian Journal of Soil Research, v.44, p.47-56, 2006.

Dikinya, O.; Hinz, C.; Aylmore, G. Influence of sodium adsorption ratio on sodium and calcium breakthough curves and hydraulic conductivity in soli columns. Australian Journal of Soil Research, v.45, p.586-597, 2007.

EMBRAPA - Empresa Brasileira de Pesquisa Agropecuária. Manual de métodos de análise de solo. 2.ed. Rio de Janeiro: CNPS, 1997. 212p.

Freire, M. B. G. S. Saturação por sódio e qualidade da água de irrigação na degradação de propriedades físicas de solos no estado de Pernambuco. Viçosa: UFV, 2001. 66p. Tese Doutorado

Freire, M. B. G. S.; Ruiz, H. A.; Ribeiro, M. R.; Ferreira, P. A.; Alvarez V. H.; Freire, F. J. Estimativa do risco de sodificação de solos de Pernambuco pelo uso de águas salinas. Revista Brasileira de Engenharia Agrícola e Ambiental, v.7, p.227232, 2003.

Harron, W. R. A.; Webster, G. R.; Cairns, R. R. Relationship between exchangeable sodium and sodium adsorption ratio in a solonetzic soil association. Canadian Journal of Soil Science, v.63, p.461-467, 1983.

Matos, A. T. Poluição ambiental: Impactos no meio físico. Viçosa: UFV, 2010. 260p.

Matos, A. T. Qualidade do meio físico ambiental: Práticas de laboratório. Viçosa: Ed. UFV, 2012. 150p.

Miranda, M. A.; Oliveira, E. E. M.; Santos, K. C. F.; Freire, M. B. G. S.; Almeida, B. G. Condicionadores químicos e orgânicos na recuperação de solo salino-sódico em casa de vegetação. Revista Brasileira de Engenharia Agrícola e Ambiental, v.15, p.484-490, 2011.

Paliwal, K. V.; Gandhi, A. P. Effect of salinity, SAR, Ca:Mg ratio in irrigation water, and soil texture on the predictability of exchangeable sodium percentage. Soil Science, v.122, p.85-90, 1976.

Paliwal, K. V.; Maliwal, G. L.; Gandhi, A. P. Prediction of exchangeable sodium percentage from cation exchange equilibria. Geoderma, v.6, p.75-78, 1971.

Rengasamy, P. Clay dispersion in relation to changes in the electrolyte composition of dialysed red-brown earths. Journal of Soil Science, v.34, p.723-732, 1983.

Schaefer, C. E. G. R.; Fabris, J. D.; Ker, J. C. Minerals in the clay fraction of Brazilian Latosols (Oxisols): A review. Clay Minerals, v.43, p.137-154, 2008. 